\section{Fewer young people are joining small-scale fishery co-ops in Chile}

Chile is known for important work on their Territorial User Rights Fishery (TURF). Back in the 90s, the government enacted policies to give small-scale fishers more control over fisheries management. To participate in the TURF system, fishers join licensed fishery associations called caletas. Children of TURF members typically join the same caletas as their family. However, this is starting to change as fewer young people follow in their parents' footsteps.

Globally, small-scale fishing communities are generally aging. It's becoming more and more rare for new people to join small-scale fisheries, especially younger people, so the age demographics of these fisheries are skewing older over time. While it's usually good to diversify an area's income-generation, particularly away from a reliance on extractive activities that will be impacted by climate change, disruptions to the social fabric of communities by a changing workforce could have negative consequences.

In 2013, the authors conducted two in-person surveys of over 200 caletas members from nine communities along the coast due west of Santiago, Chile. The results suggest that over $50 \%$ of respondents believe there is no future for small-scale fisheries. Nearly all those surveyed did not want their children to become small-scale fishers themselves. Only $11 \%$ of respondents were under 40 years old, emphasizing the lack of young people entering the TURF system. The stated reasons for the stalled growth "primarily concerned working conditions (e.g., risk of injury, physical difficulty of the work, lack of family time), the appearance of 'better' options outside of fishing, and the simultaneous lack of profitability in fishing associated with declines in marine resource abundances." Competition from industrial fishing fleets was also a common complaint.

Small-scale fishery managers should take note of these shifting demographics, particularly as the membership of caletas is likely to decline over time if these trends continue. With fewer local fishers, communities will have to rely on large-scale fishing fleets for their food, which could have greater impacts on the ecosystem.

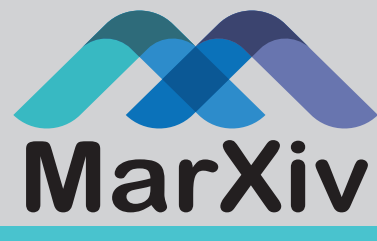

This is a summary of: Gone fishing? Intergenerational cultural shifts can undermine common property comanaged fisheries

Accessible at: https://marxiv.org/tpkdu

Authors: Jordan Tam, Kai Chan, Terre Satterfield, G.G. Singh, Stefan Gelcich

Added to MarXiv: May 2018

Published: Marine Policy, 2018

Suggested Citation: Fewer young people are joining small-scale fishery co-ops in Chile. OCTO (2018). DOI: 10.31230/osf. io/4kt5g

See more MarXiv summaries at https://www.marxivinfo.org/ summaries

Join the MarXiv Summaries monthly newsletter at https:// oct.to/marxivsum

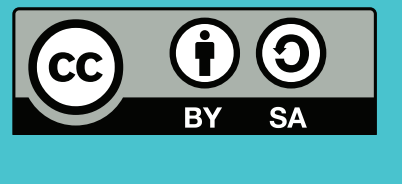

MarXiv is an ОСТO Initiative
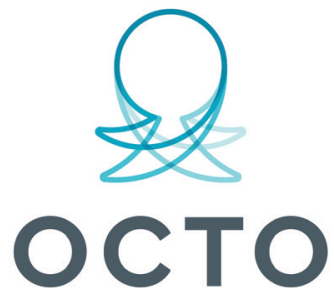

OPEN COMMUNICATIONS FOR THE OCEAN 